\title{
The Sandy Desilication Product Process Concept
}

\author{
JAMES VAUGHAN ${ }^{1,},{ }^{1,3}$ HONG PENG,${ }^{1,4}$ DILINI SENEVIRATNE, ${ }^{1}$ \\ HARRISON HODGE, ${ }^{1}$ WILLIAM HAWKER,${ }^{1}$ PETER HAYES, ${ }^{1}$ and \\ WARREN STAKER ${ }^{2}$
}

\begin{abstract}
1.-School of Chemical Engineering, Metallurgy Program, The University of Queensland, Brisbane, Australia. 2.-Rio Tinto, Refinery Support Aluminium, Brisbane, Australia. 3.-e-mail: james.vaughan@uq.edu.au.4.—e-mail: h.peng2@uq.edu.au
\end{abstract}

\begin{abstract}
Reactive silica is the most detrimental impurity in bauxite. When bauxite is contacted with Bayer liquor, reactive silica dissolves and then precipitates as a sodium aluminum silicate known as the desilication product (DSP), which is discarded along with the bauxite residue and maintained in long-term storage facilities. DSP recycling using bauxite residue lime sinter-leach is prohibitively expensive due to the high energy requirement for heating as well as high investment costs. In the sandy desilication product process, DSP is coarsened by controlling the desilication conditions, which enables the DSP fraction of the residue to be concentrated by physical separations. The DSP concentrate can then be recycled by sinter-leaching, whereby sodium and aluminum are returned to the Bayer process, reducing the burden associated with bauxite residue and facilitating total residue treatment options. Results are presented herein demonstrating DSP particle enlargement by seeding the reaction and controlling the supersaturation.
\end{abstract}

\section{INTRODUCTION}

The principal components of bauxite ores are aluminum-, iron-, and silicon-bearing minerals. In the Bayer process for recovery of alumina from bauxite ${ }^{1}$ aluminum is dissolved into hot alkaline solution whilst iron is relatively insoluble. "Reactive silica" in the form of silicate minerals, such as kaolinite, typically dissolves and reprecipitates as sodium aluminum hydrosilicate, known as the desilication product (DSP). Desilication of the leach liquor for low-temperature digestion refineries is essential to meet alumina product specifications, minimize scale formation on heat transfer surfaces, and remove other impurities from the Bayer liquor. However, precipitation of DSP is costly, as sodium hydroxide (the key reagent in the Bayer process) and aluminum (element for the product alumina) are lost, being discarded as part of the bauxite residue. It has been stated that bauxites with reactive silica concentrations greater than approximately $6 \mathrm{wt} \%$ to 8 wt.\% cannot be processed economically ${ }^{2,3}$ due to losses of sodium hydroxide, which is approximately 1 tonne of $\mathrm{NaOH}$ per tonne of reactive silica due to formation of DSP. Furthermore, DSP in the bauxite residue adds to the complexity of processes for bauxite residue neutralization, tailings area remediation, ${ }^{4}$ and recycling the residue for iron recovery, as well as subsequent use of residue in building materials. ${ }^{5}$

\section{REACTIVE SILICA AND BAYER PROCESS DESILICATION}

Reactive silica in bauxite can be present in many forms, such as kaolinite or other clay minerals. The rate of dissolution of quartz in Bayer liquors is generally slow, but measurable dissolution can be obtained at high-temperature digestion conditions. Typically, industrially processed bauxites currently contain between 0.1 wt. $\%$ and 7 wt. $\% \mathrm{SiO}_{2}$ in the form of reactive silica. The aluminum component of DSP is generally not regarded as a loss if the reactive silica is from clay, as the source of aluminum is the clay, but if quartz reacts, the formation of DSP results in a net loss of aluminum that would otherwise have become the alumina product.

Ideally, the presence of clays would be avoided by preprocessing of the ore to physically separate the clay minerals from the bauxite ahead of the Bayer process; this could be achieved through selective mining, washing and screening, or flotation, for 
example. Unfortunately, for some bauxites, the reactive silica is intimately associated and dispersed with other minerals, meaning that effective physical separation of reactive silica from these bauxite ores is not possible. ${ }^{6}$ For these bauxites, the dissolution of kaolinite in the Bayer sodium hydroxide solution is described by Eq. 1 .

$$
\begin{aligned}
& 3 \mathrm{Al}_{2} \mathrm{Si}_{2} \mathrm{O}_{5}(\mathrm{OH})_{4(\mathrm{~s})}+18 \mathrm{NaOH}_{(\mathrm{aq})} \\
& \quad \rightarrow 6 \mathrm{Na}_{2} \mathrm{SiO}_{3(\mathrm{aq})}+6 \mathrm{NaAl}(\mathrm{OH})_{4(\mathrm{aq})}+3 \mathrm{H}_{2} \mathrm{O}_{(\mathrm{l})}
\end{aligned}
$$

When bauxite is contacted with Bayer liquor, the concentration of silicate in solution is increased and it becomes supersaturated with respect to the desilication product (DSP). The main desilication product for atmospheric-pressure reactors and lowtemperature pressure digestion reactors is the sodalite phase, which may involve an intermediate amorphous precipitate. ${ }^{7,8}$ The overall reaction for the precipitation of sodalite from Bayer liquors is described by Eq. 2,

$$
\begin{aligned}
& 6 \mathrm{Na}_{2} \mathrm{SiO}_{3(\mathrm{aq})}+6 \mathrm{NaAl}(\mathrm{OH})_{4(\mathrm{aq})}+\mathrm{Na}_{2} X_{(\mathrm{aq})} \\
& \rightarrow \mathrm{Na}_{6}\left[\mathrm{Al}_{6} \mathrm{Si}_{6} \mathrm{O}_{24}\right] \cdot \mathrm{Na}_{2} X \cdot 3 \mathrm{H}_{2} \mathrm{O}_{(\mathrm{s})}+12 \mathrm{NaOH}_{(\mathrm{aq})} \\
&+3 \mathrm{H}_{2} \mathrm{O}_{(\mathrm{l})}
\end{aligned}
$$

where $X=\mathrm{SO}_{4}{ }^{2-}, \mathrm{CO}_{3}{ }^{2-}, \mathrm{C}_{2} \mathrm{O}_{4}{ }^{2-}, 2 \mathrm{Al}(\mathrm{OH})_{4}^{-}, 2 \mathrm{Cl}^{-}$, or $2 \mathrm{OH}^{-} .9,10$ The amount of associated water can vary depending on the precipitation conditions and drying procedures prior to analysis. The composition of the DSP can also vary substantially due to the variety of anions that can be incorporated. DSP therefore plays an important beneficial role in the Bayer process by removing anionic impurities from the Bayer liquor. Many empirical correlations for the solubility of DSP have been presented for Bayer liquors. These solubility correlations have been summarized, ${ }^{11}$ but the DSP solubility can vary significantly depending on the solution impurity profile, temperature, and type of DSP formed. A comprehensive DSP solubility model in Bayer liquor has yet to be developed.

At the higher process temperatures required for boehmite digestion $\left(220^{\circ} \mathrm{C}\right.$ to $\left.280^{\circ} \mathrm{C}\right)$, longer residence times, and in the presence of $\mathrm{Ca}$, formation of cancrinite DSP $\left(\mathrm{Na}_{6}\left[\mathrm{Al}_{6} \mathrm{Si}_{6} \mathrm{O}_{24}\right] \cdot 2 \mathrm{CaCO}_{3} \cdot 2 \mathrm{H}_{2} \mathrm{O}\right)$ is favored. $^{3,12}$ Cancrinite has also been identified as a major component of digester scale that builds up over several months at a typical low digestion temperature of $145^{\circ} \mathrm{C} .{ }^{13}$ Aggressive conditions of high temperature and longer residence time also promote quartz dissolution, therefore the benefit of targeting cancrinite is not high, if any. The process economics of targeting cancrinite or other calciumrich DSPs also depends on the relative price of $\mathrm{CaO}$ and $\mathrm{NaOH}$.

In the Bayer process, the particle size of the bauxite ore is first reduced through grinding, then it is sent to slurry transfer tanks, which are typically maintained at about $70^{\circ} \mathrm{C}$. Pre-desilication is usually carried out in a series of continuously stirred tank reactors in which the temperature is maintained at $90^{\circ} \mathrm{C}$ to $100^{\circ} \mathrm{C}$ with high solids loading; residence times of $6 \mathrm{~h}$ to $24 \mathrm{~h}$ are used to ensure adequate conversion of kaolinite to DSP ahead of digestion. The desilication product formed at pre-desilication conditions is said to be much finer than that formed at low-temperature digestion conditions, ${ }^{2}$ thus providing a large active particle surface area to promote desilication reaction kinetics. The DSPs that form during pre-desilication (sodalite and potentially zeolite A) can partly dissolve and reprecipitate in subsequent digestion processes.

For bauxites that have high concentrations of reactive silica, a number of different desilication strategies have been proposed to mitigate the costs associated with this reactive silica. Examples of the key process options that have been described are summarized in Table I, and additional discussion can be found in the review of Smith. ${ }^{3}$ In the Sumitomo process, the digestion residence time is reduced to $<10 \mathrm{~min}$, which provides improved selectivity for gibbsite dissolution compared with reactive silica dissolution. For the Sumitomo process to be effective, the residence time during clarification also needs to be significantly shortened, preferably by pressure decantation, which increases the complexity of the equipment design and operation. The relatively high $\mathrm{SiO}_{2}$ concentration requires post-desilication, which is preferably carried out with seed and at digestion temperature. To overcome the associated challenge of lower liquor productivity due to the low digestion temperature and short residence time, Sumitomo suggested sweetening the digestion liquor through a second stage of digestion. ${ }^{14}$ The improved low-temperature digestion process (ILTD) also operates on the principle of differential extraction as used in the Sumitomo process. In the ILTD process, the Bayer liquor has a lower reactive hydroxide concentration, for example, initial $[\mathrm{NaOH}]$ of $3.3 \mathrm{~mol} / \mathrm{L}$ versus $4.7 \mathrm{~mol} /$ $\mathrm{L}$ for the conventional Bayer process, with a resulting exit $[\mathrm{NaOH}]$ of $0.67 \mathrm{~mol} / \mathrm{L}$, enabling the gibbsite to be selectively dissolved while the reactive silica remains relatively unreacted. The silicates that are dissolved and are in the overflow of a pressure decanter or in the filtrate of a hyperbaric filter are recovered in pure form in a seeded postdigestion desilication stage that operates at elevated pressure and a temperature close to that used in the digestion. The bauxite residue (BR) of the ILTD process has a low chemically combined soda content and opens attractive ways for valorization of BR. ${ }^{15,16}$ In the Rio Tinto (Comalco) process, reactive silica is selectively dissolved from bauxite in a separate circuit ahead of the Bayer process. The selectivity for reactive silica mineral dissolution is achieved using a liquor with high concentrations of $\mathrm{NaOH}_{(\mathrm{aq})}$ and $\mathrm{NaAl}(\mathrm{OH})_{4(\mathrm{ag})}$, which permits higher concentrations of $\mathrm{Na}_{2} \mathrm{SiO}_{3(\mathrm{aq})}$ in solution to be achieved 
Table I. Examples of operating parameters of process modifications for high-silica bauxite

\begin{tabular}{|c|c|c|c|c|c|c|}
\hline $\begin{array}{l}\text { Process } \\
\text { modification } \\
\end{array}$ & $\begin{array}{l}\text { Conventional } \\
\text { Bayer process } \\
\end{array}$ & Sumitomo & ILTD & Rio Tinto & $\begin{array}{c}\text { Submolten } \\
\text { salt } \\
\end{array}$ & IPE \\
\hline Reference & Ref. 3 & Refs. 17,18 & Ref. 19 & Ref. 20 & Ref. 21 & Ref. 22 \\
\hline Ore type & Gibbsitic & Gibbsitic & Gibbsitic & $\begin{array}{l}\text { Gibbsitic boehmi- } \\
\text { tic }\end{array}$ & Diasporic & Diasporic \\
\hline Bauxite $\left[\mathrm{SiO}_{2}\right](\%)$ & 5.8 & 5.5 & 3.1 & 5.8 & 8.4 & 8.4 \\
\hline Bauxite $\left[\mathrm{Al}_{2} \mathrm{O}_{3}\right](\%)$ & 56 & 50 & 55 & 56 & 64 & 56 \\
\hline Initial solid loading $(\mathrm{g} / \mathrm{L})$ & 200 & 220 & 222 & 200 & 400 & 200 \\
\hline Initial particle size ( $\mathrm{mm})$ & $<0.5$ & $<0.3$ & $<0.5$ & $<0.5$ & $<0.1$ & $<0.1$ \\
\hline $\begin{array}{l}\text { Initial liquor } \\
{[\mathrm{NaOH}](\mathrm{mol} / \mathrm{L})}\end{array}$ & 4.7 & 4.9 & 3.3 & 7.6 & 25 & 10 \\
\hline $\begin{array}{l}\text { Initial liquor } \\
\quad\left[\mathrm{Al}(\mathrm{OH})_{3}\right](\mathrm{mol} / \mathrm{L})\end{array}$ & 2.0 & 1.6 & 1.7 & 4.7 & 0 & 5.9 \\
\hline Temperature $\left({ }^{\circ} \mathrm{C}\right)$ & 145 & 135 & 150 & 95 & 135 & 90 \\
\hline Residence time (min) & 45 & $<10$ & $<10$ & $>20$ & $<20$ & $>120$ \\
\hline
\end{tabular}

and remain stable through solid-liquid separation. One of the challenges with this option is the recovery of the silicate from solution, which is then recycled. The desilication rate can be enhanced by adding water, but the water must be removed, which requires an additional unit operation and energy cost. The options briefly discussed so far have been developed specifically for processing of gibbsitic bauxites. In the submolten salt process, concentrated $\mathrm{NaOH}$ solutions (50 wt.\%) are used to selectively dissolve reactive silica from diasporetype bauxite at $135^{\circ} \mathrm{C}$ for $20 \mathrm{~min}$, resulting in an increase of the $\mathrm{Al} / \mathrm{Si}$ ratio in the solids from 7.6 to 12. The Institute of Process Engineering (IPE) method is similar to the Rio Tinto process but tailored to diasporic bauxite.

\section{BAUXITE RESIDUE}

Bauxite residue is an alkaline and mineralogically complex material having a fine particle size distribution. Most bauxite residue is maintained in long-term storage facilities, and globally the material is being generated at a rate greater than 150 $\mathrm{Mt} /$ year. ${ }^{5}$ Bauxite residue management, reuse, and chemistry were comprehensively reviewed in a three-part series of papers in Hydrometallurgy. ${ }^{4,23,24}$ The composition and size distribution of bauxite residues can vary significantly depending on the bauxite feed and processing conditions. The main components of lateritic bauxite processing residues are typically $\mathrm{Fe}_{2} \mathrm{O}_{3}$ (hematite), $\mathrm{Na}_{8} \mathrm{Al}_{6}$ $\mathrm{Si}_{6}(\mathrm{OH})_{24} \mathrm{CO}_{3}$ (sodalite), $\mathrm{TiO}_{2}$ (anatase), $\gamma-\mathrm{AlO}(\mathrm{OH})$ (boehmite), and $\mathrm{SiO}_{2}$ (quartz). The sodium and aluminum concentrations in bauxite residues also vary widely depending on the bauxite processed and processing conditions. Industrial bauxite residues contain between $1 \%$ and $12 \% \mathrm{Na}_{2} \mathrm{O}$ and $7 \%$ and $33 \%$ $\mathrm{Al}_{2} \mathrm{O}_{3}{ }^{4}$ Also present in the residues are low concentrations of relatively valuable elements such as $\mathrm{Ga}, \mathrm{V}, \mathrm{Sc}, \mathrm{La}$, and Y. However, due to the alkalinity and mineral associations, it is difficult to recover valuable minor components without also processing the major phases.

Processing bauxite high in reactive silica results in high sodium and aluminum in the residue, mainly in the form of sodalite. When treating high-silica bauxite, the provision of replacement sodium hydroxide becomes a major component of the refinery operating cost. With conventional desilication, sodalite particles are fine and associated with the remainder of the fine bauxite residue. In one example, ${ }^{25}$ the bauxite residue $d_{50}$ was $20 \mu \mathrm{m}$ and the sodalite grains were found to be extremely fine and intermingled with hematite and anatase, precluding the possibility of effective physical separation of DSP for this bauxite residue.

\section{SERIAL COMBINED BAYER-SINTERING PROCESS}

The serial combined Bayer-sintering process is an industrial technology for reprocessing bauxite residues that contain significant concentrations of $\mathrm{Al}$ and $\mathrm{Na}$. The process has been applied in China and Kazakhstan, where it is used to reprocess bauxite residues from Bayer refineries treating low-quality diasporic ore. ${ }^{26}$

The process begins by mixing $\mathrm{BR}$ with limestone $\left(\mathrm{CaCO}_{3}\right)$ and sodium carbonate $\left(\mathrm{Na}_{2} \mathrm{CO}_{3}\right)$ to approximately achieve molar ratios of $\mathrm{Na}: \mathrm{Al}=1.3$ and $\mathrm{Ca}: \mathrm{Si}=2$. This sinter charge is then heated to approximately $1080^{\circ} \mathrm{C}$ with the objective of converting the $\mathrm{Na}$ - and Al-bearing phases to aqueous soluble sodium aluminate, and fairly insoluble calcium silicate. ${ }^{26}$ The primary overall reaction is shown in Eq. 3.

$$
\begin{aligned}
& \mathrm{Na}_{6}\left[\mathrm{Al}_{6} \mathrm{Si}_{6} \mathrm{O}_{24}\right] \cdot \mathrm{Na}_{2}(\mathrm{OH})_{2} \cdot 3 \mathrm{H}_{2} \mathrm{O}_{(\mathrm{s})} \\
& \quad+2 \mathrm{Al}(\mathrm{OH})_{3(\mathrm{~s})}+12 \mathrm{CaCO}_{3(\mathrm{~s})} \\
& \quad \rightarrow 8 \mathrm{NaAlO}_{2(\mathrm{~s})}+6 \mathrm{Ca}_{2} \mathrm{SiO}_{4(\mathrm{~s})}+7 \mathrm{H}_{2} \mathrm{O}_{(\mathrm{g})}+12 \mathrm{CO}_{2(\mathrm{~g})}
\end{aligned}
$$


A detailed set of reactions and a description of the reaction pathways during the sintering process were recently described based on quantitative x-ray diffraction analysis using Rietveld refinement of the phases formed as a function of heat-treatment time. ${ }^{27}$ In the subsequent leaching of the sinter product, dilute caustic solution is used to selectively dissolve sodium aluminate (Eq. 4). The pregnant liquor can then be separated from the solid residue. A post-desilication unit is typically required to generate a liquor of sufficient quality to recycle back to the Bayer process.

$$
\mathrm{NaAlO}_{2(\mathrm{~s})}+2 \mathrm{H}_{2} \mathrm{O}_{(\mathrm{l})} \rightarrow \mathrm{NaAl}(\mathrm{OH})_{4(\mathrm{aq})}
$$

While the serial combined Bayer-sintering process is technically feasible and industrially proven, it is not economically attractive due to high capital, reagent, and energy costs. The key reagent is $\mathrm{CaCO}_{3}$, which is required in stoichiometric excess for residues high in $\mathrm{Fe}_{2} \mathrm{O}_{3}$ due to the formation of calcium ferrites. The formation of calcium ferrites is undesirable since it not only consumes additional Ca but also compromises the aluminum recovery, as $\mathrm{Al}$ is incorporated into the calcium ferrite solid solutions. In processing high-iron BR, sodium ferrites can also form, which can result in a lower liquidus temperature and increased liquid fractions during processing. To counteract the negative effects of these side reactions with $\mathrm{Fe}_{2} \mathrm{O}_{3}$, reductive sintering can be used. By subjecting the material to reducing conditions, the $\mathrm{Fe}_{2} \mathrm{O}_{3}$ can be converted to $\mathrm{Fe}_{3} \mathrm{O}_{4}$ or metallic iron, thus avoiding extensive reactions with $\mathrm{CaCO}_{3}$ or $\mathrm{Na}_{2} \mathrm{CO}_{3}{ }^{28}$

The main operating expense of the serial combined Bayer-sintering process is the energy required to evaporate water and heat the sinter mixture to the high reaction temperature. The energy intensity of the process was reported to be $42 \mathrm{GJ} / \mathrm{t}-\mathrm{Al}_{2} \mathrm{O}_{3}$, compared with $12 \mathrm{GJ} / \mathrm{t}-\mathrm{Al}_{2} \mathrm{O}_{3}$ for the conventional Bayer process. ${ }^{29}$ The capital and energy intensity are thus the most significant impediments to greater industrial application of the process.

\section{DSP ENLARGEMENT}

A limited number of papers report the DSP particle size distributions formed during Bayer processing. ${ }^{30-43}$ These papers highlight that, despite seeding being an effective means of increasing the kinetics of desilication, only small increases in the individual seed crystal size are achieved in seeding trials ( $1 \mu \mathrm{m}$ to $2 \mu \mathrm{m}$ increase). Jones and Smith ${ }^{40}$ and Zeng and $\mathrm{Li}^{41}$ reported that seed with average particle size of $5 \mu \mathrm{m}$ increased to $10 \mu \mathrm{m}$, and $8 \mu \mathrm{m}$ increased to $19 \mu \mathrm{m}$. However, it is not clear whether this observed increase in average crystal size was the result of individual crystal growth or crystal agglomeration. The growth rates of DSP crystals appear to be slow under Bayer conditions, and the most promising way of achieving coarse particles under Bayer pre-desilication conditions is by focusing on agglomeration. While evidence of agglomeration has been observed, ${ }^{31-33,37}$ a systematic study of DSP agglomeration and DSP coarsening has not been conducted to date. Organic additives are used to tune the particle size of crystals in the zeolite manufacturing industry. To test their impact on DSP under synthetic Bayer conditions, crystallization of DSP in the presence of 15 organic additives was studied. ${ }^{44}$ Both scanning electron microscopy (SEM) and AccuSizer data showed that sodium dodecyl sulfate, an anionic surfactant, at $250 \mathrm{mg} / \mathrm{L}$ to $750 \mathrm{mg} / \mathrm{L}$ enhanced individual DSP crystal growth and increased the proportion of agglomerates in the $8 \mu \mathrm{m}$ to $40 \mu \mathrm{m}$ size range and reduced the proportion of DSP fines $(<1 \mu \mathrm{m})$.

In terms of practical application of DSP seeding, a process for the removal of silicate from an alkaline sodium aluminate solution, by contacting with a slowly stirred bed of coarse silica sand or coarse silica and coarse crushed scale particles of sodalite, was patented. ${ }^{45}$ The median particle size for the quartz and the sodalite was $\sim 1.2 \mathrm{~mm}$. The best desilication or DSP capture was achieved at $140^{\circ} \mathrm{C}$, precipitating $0.5 \mathrm{~g} / \mathrm{L} \mathrm{SiO}_{2}$ when using $920 \mathrm{~g} / \mathrm{L}$ pure sand as seed. Seeding has also been said to improve desilication rates during post-desilication. Achieving a larger particle size in these applications can be counterproductive, as the active surface area to volume ratio is decreased.

\section{EXPERIMENTAL}

To demonstrate the ability to produce large DSP particles and study the effects of silicate supersaturation and seed concentration, variable-volume reactor tests were conducted. A $300-\mathrm{mL}$ solution targeting an initial composition of $2 \mathrm{M} \mathrm{NaAl}(\mathrm{OH})_{4}$, $5 \mathrm{M} \mathrm{NaOH}$, and $0.1 \mathrm{M} \mathrm{Na}_{2} \mathrm{CO}_{3}$ was made. The reactor was heated to $90^{\circ} \mathrm{C}$, and sodium metasilicate solution was added to target an initial $\mathrm{Na}_{2} \mathrm{SiO}_{3}$ concentration of $0.03 \mathrm{M}$ (equivalent to $1.8 \mathrm{~g} / \mathrm{L} \mathrm{SiO}_{2}$ ). Two solutions were pumped into the reactor: (1) $10 \mathrm{M} \mathrm{NaOH}, 5 \mathrm{M} \mathrm{NaAl}(\mathrm{OH})_{4}$ and (2) $50 \mathrm{~g} / \mathrm{L} \mathrm{SiO}_{2}$ made from sodium metasilicate. The reactor volume was allowed to increase over time. Silicate addition rates to reflect silicate dissolution consistent with industrial pre-desilication at a relatively low bauxite solids loading of $300 \mathrm{~g} / \mathrm{L}$ with different reactive silica contents $(7 \%, 10 \%$, and $13 \%)$, assuming $80 \%$ reacts in $6 \mathrm{~h}$, were used. This corresponded to $0.18 \mathrm{ml} / \mathrm{min}, 0.29 \mathrm{~mL} / \mathrm{min}$, and $0.46 \mathrm{~mL} / \mathrm{min}$ of the silicate solution (2), respectively. Solution (1) was added at a constant rate to maintain approximately constant $\mathrm{NaOH}$ and $\mathrm{NaAl}(\mathrm{OH})_{4}$ concentrations during the tests. A coarse DSP seed was used, synthesized at $100^{\circ} \mathrm{C}$ in an autoclave over $72 \mathrm{~h}$ in $0.5 \mathrm{M}$ $\mathrm{NaAl}(\mathrm{OH})_{4}, 6 \mathrm{M} \mathrm{NaOH}$, and $0.02 \mathrm{M} \mathrm{Na}_{2} \mathrm{CO}_{3}$ solution with $0.1 \mathrm{M} \mathrm{SiO}_{2}$ added up front in the form of sodium metasilicate, then wet screened to separate 
the coarse $>\sim 20 \mu \mathrm{m}$ size fraction. The total solution volume of $2.5 \mathrm{~L}$ produced on average $35 \mathrm{~g}$ of DSP, of which $23 \mathrm{~g}(\sim 67 \%$ wt. $\%)$ was $>20 \mu \mathrm{m}$. DSP enlargement tests were run for $\sim 6 \mathrm{~h}$, and subsamples were collected for particle size distribution analysis using an AccuSizer $780 \mathrm{AD}$ and solution silicate determination by molybdate blue and ultraviolet (UV) spectroscopy. The AccuSizer particle count data recorded were converted to volume $\%$ by assuming that the particles were spherical and a minor portion of particles $>80 \mu \mathrm{m}$ were removed for analysis. To investigate the particle shapes and morphologies, SEM secondaryelectron images were obtained for carbon-coated particles using either a JOEL JSM-7001 or JOEL JSM-6610 electron microscope at accelerating voltage of $10 \mathrm{kV}$ and working distance of approximately $10 \mathrm{~mm}$.

\section{RESULTS}

Significant DSP enlargement was observed and shown to be more effective with a relatively lower seed ratio (0.6 seed:1 DSP precipitated) and lower silicate dose rate/supersaturation $(0.18 \mathrm{~mL} / \mathrm{min}$, $\left.50 \mathrm{~g} / \mathrm{L} \mathrm{SiO}_{2}\right)$ using coarse seed $(>\sim 20 \mu \mathrm{m})$; the particle size distributions as a function of time for this condition are shown in Fig. 1, showing that the number of fine particles was reduced and most of the particles were above $30 \mu \mathrm{m}$. The silicate concentration in solution over the course of this test (as $\mathrm{SiO}_{2}$ g/L equivalent) in comparison with the no-seed case is shown in Fig. 2, and while the no-seed case showed a typical desilication curve as seen during pre-desilication of bauxite, the seeded case showed a much slower increase in silicate concentration.
Comparison of the particle structure of the seed DSP (Figs. 3 and 4) with the product from the seeded growth experiment (Figs. 5 and 6) reveals that the initial agglomerates of spherical-shaped subparticles composed of platelet-shaped crystals filled in and there are signs of secondary nucleation of new DSP particles on the surface of the seed.

In summary, DSP enlargement at these conditions is dominated by particle growth with other contributing mechanisms being agglomeration of smaller particles and preferential secondary nucleation where the nuclei likely become incorporated into the existing particles.

\section{SANDY DSP PROCESS}

In the sandy desilication process (Fig. 7), the bauxite pre-desilication stage is modified to promote enlargement of the DSP particles through reaction seeding and supersaturation control. The pre-desilication reactors operate at elevated temperature but atmospheric pressure. Following digestion, the thickened slurry proceeds to particle-particle physical separations by multistage hydrocycloning ${ }^{46}$ or possibly with novel equipment such as the REFLUX ${ }^{\mathrm{TM}}$ classifier. ${ }^{47}$ Hydrocyclones are already well established in the Bayer process for bauxite grinding, sand separation from red mud, sand washing, gibbsite (alumina hydrate) classification and size control, gibbsite thickening and deliquoring, separation of oxalates, cooling tower water clean-up, and lime slurry degritting. ${ }^{48}$ The classification circuit rejects the majority of the slowsettling bauxite residue. A DSP seed stream with fine particle sizes is recycled back to pre-desilication, which promotes growth and agglomeration as

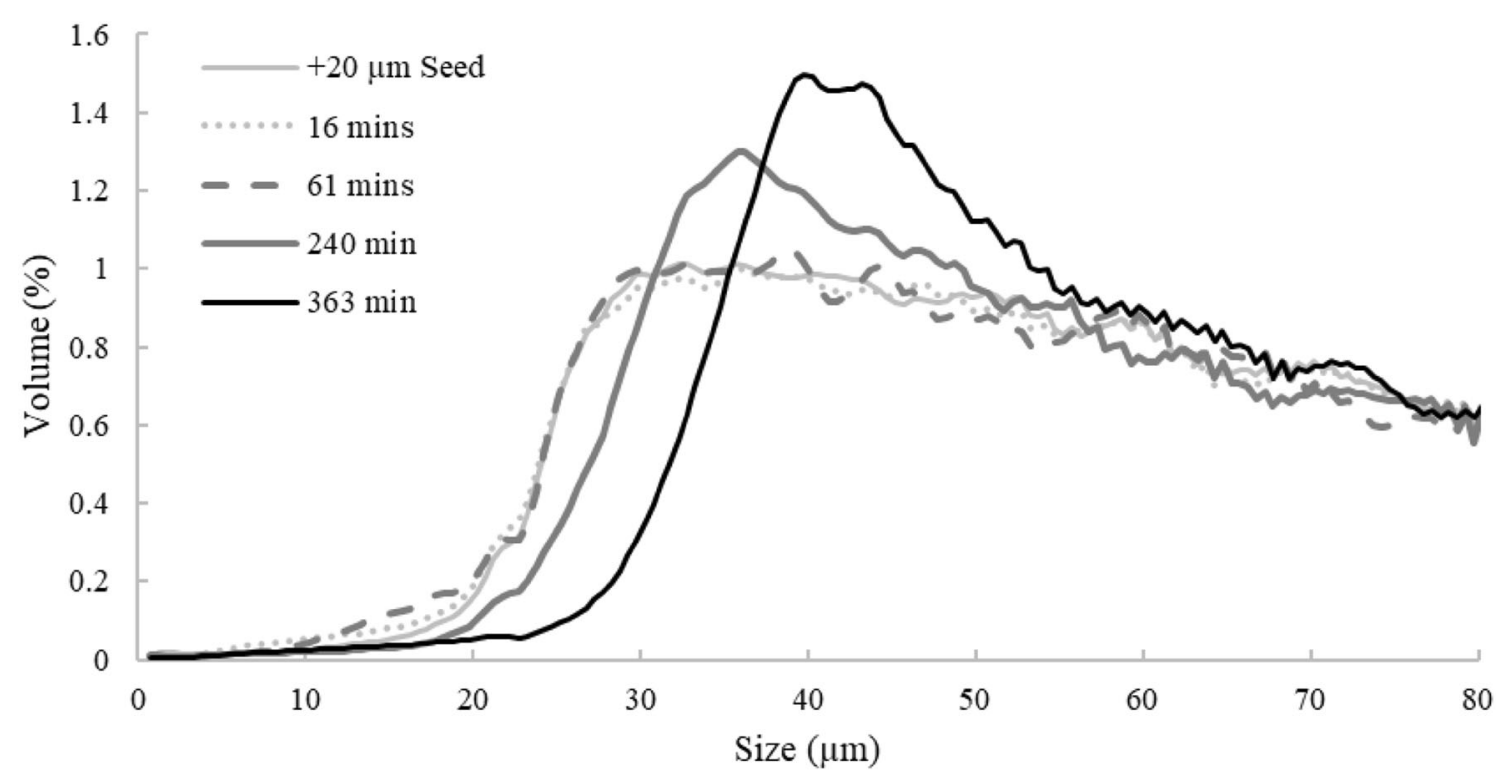

Fig. 1. DSP particle size distribution (vol.\%) as a function of time for relatively lower seed ratio ( 0.6 seed: 1 DSP precipitated) and lower silicate dose rate $\left(0.18 \mathrm{~mL} / \mathrm{min} 50 \mathrm{~g} / \mathrm{L} \mathrm{SiO}_{2}\right)$ using a coarser DSP seed. 


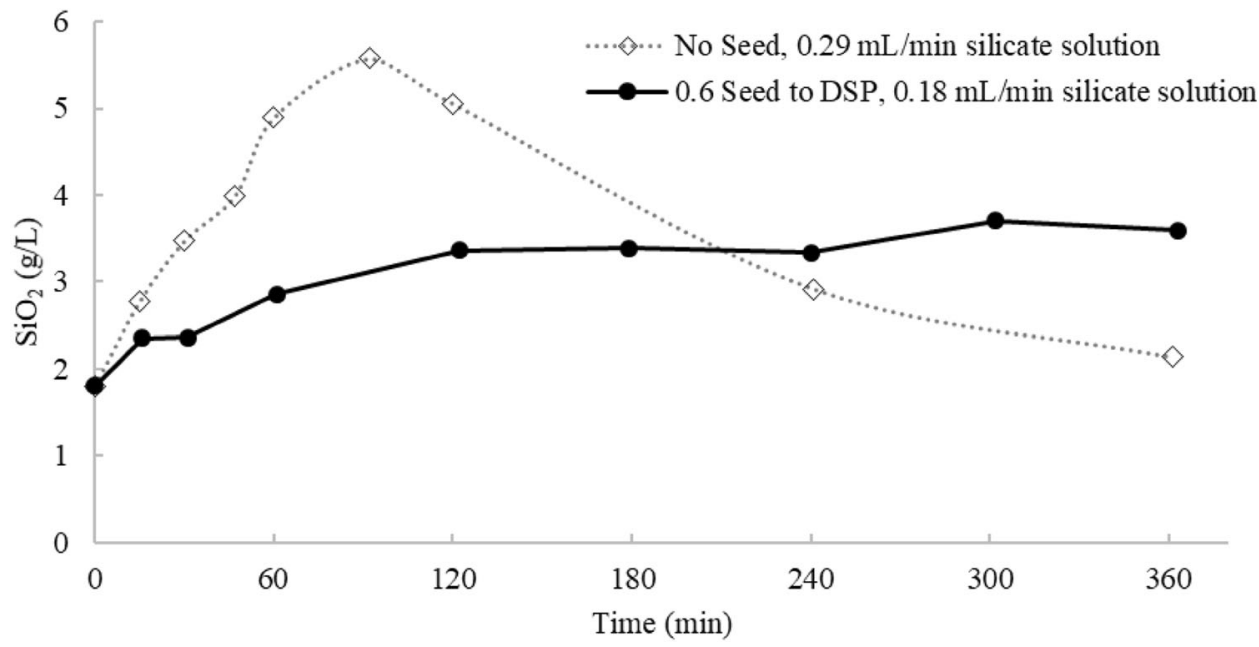

Fig. 2. Variable-volume reactor precipitation of $\mathrm{DSP}$, silicate concentration as a function of time at $90^{\circ} \mathrm{C}$. Initial solution $300 \mathrm{~mL}$ of $2 \mathrm{M}$ $\mathrm{NaAl}(\mathrm{OH})_{4}, 5 \mathrm{M} \mathrm{NaOH}$, and $0.1 \mathrm{M} \mathrm{Na}_{2} \mathrm{CO}_{3}$ solution; $0.03 \mathrm{M} \mathrm{Na}_{2} \mathrm{SiO}_{3}$ with $50 \mathrm{~g} / \mathrm{L} \mathrm{SiO}$ was added at specified rate along with $10 \mathrm{M} \mathrm{NaOH}, 5 \mathrm{M}$ $\mathrm{NaAl}(\mathrm{OH})_{4}$ to maintain approximately constant $\mathrm{NaOH}$ and $\mathrm{NaAl}(\mathrm{OH})_{4}$ concentrations throughout the experiment.

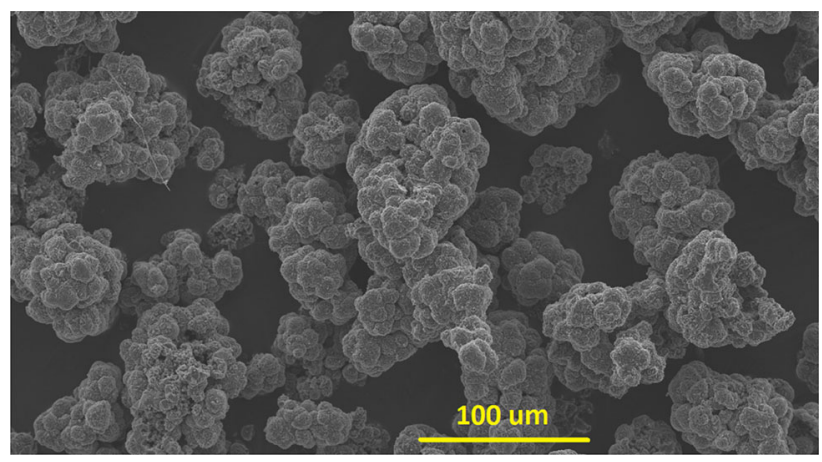

Fig. 3. Scanning electron micrograph of the DSP seed, low magnification.

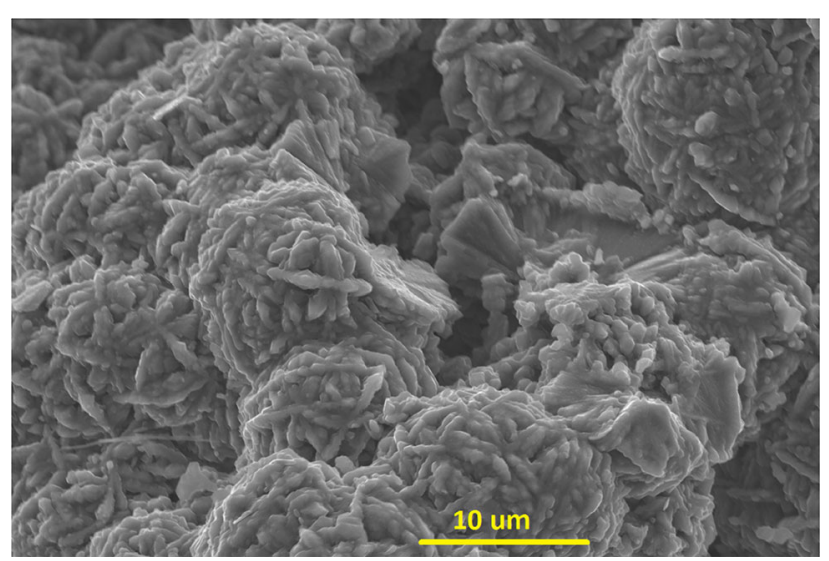

Fig. 4. Scanning electron micrograph of the DSP seed, high magnification.

opposed to nucleation of fine DSP. The coarsest DSP particles are then recovered from the process in a concentrated form.

The $\mathrm{Na}$ and $\mathrm{Al}$ contained in the coarse DSP concentrate can be recycled back to the Bayer refinery by lime sintering followed by leaching the

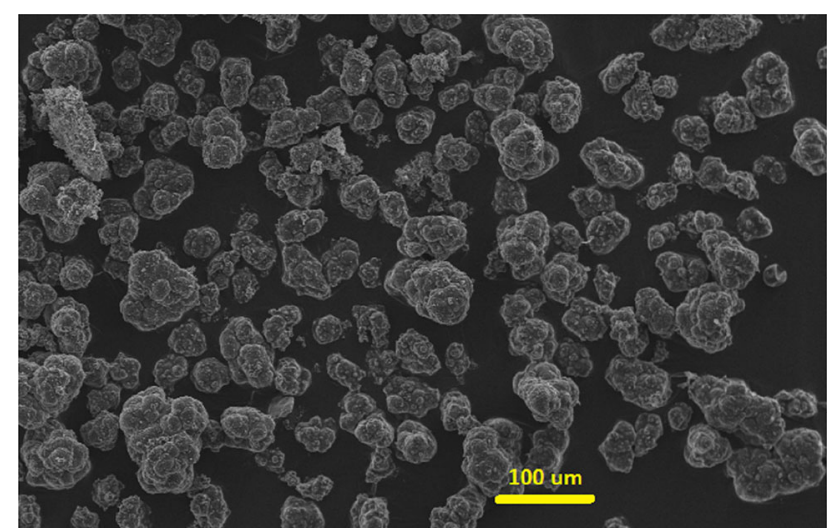

Fig. 5. Scanning electron micrograph of coarsened DSP product from the seeded experiment after $6 \mathrm{~h}$, low magnification.

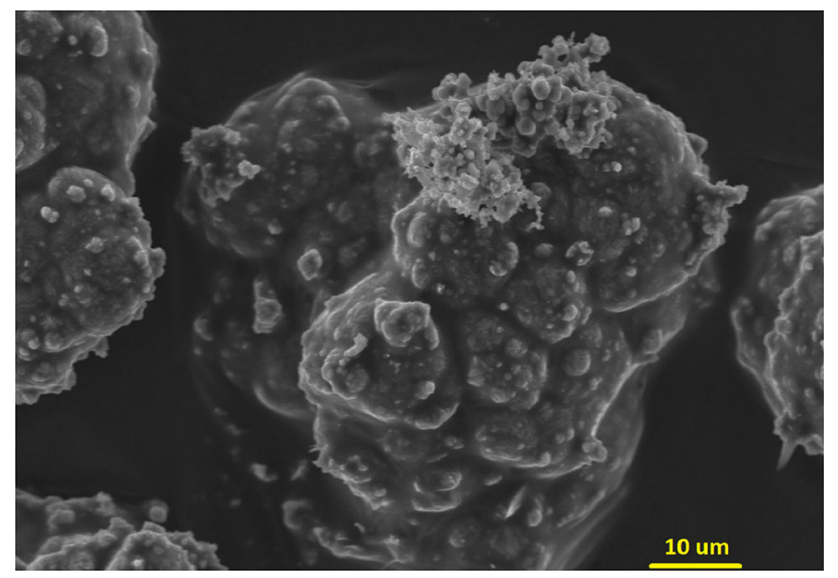

Fig. 6. Scanning electron micrograph of coarsened DSP product from the seeded experiment after $6 \mathrm{~h}$, high magnification.

sinter. The unit operations will be the same as in the serial combined Bayer-sintering process, but the feed material will differ in that the DSP fraction 


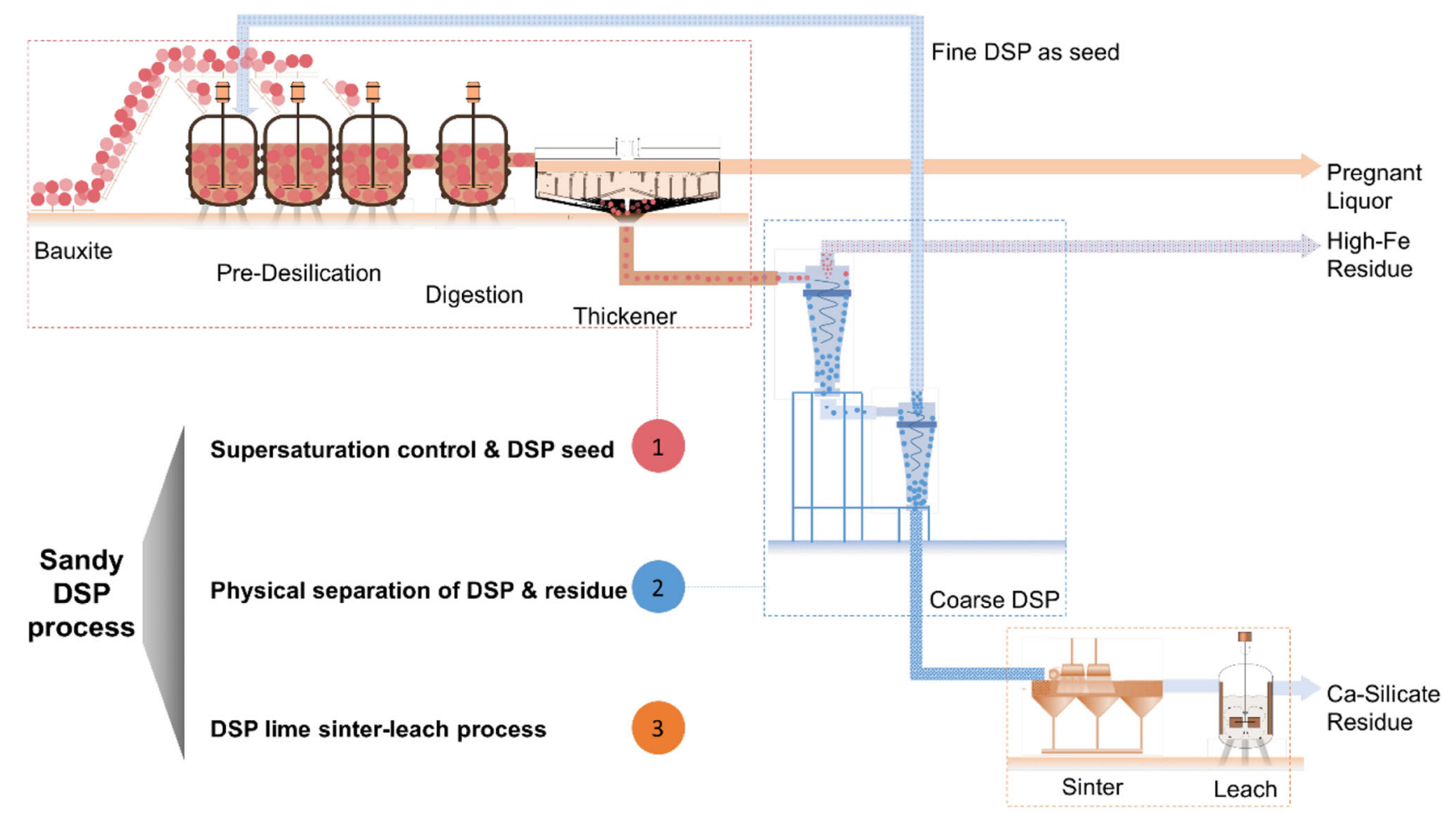

Fig. 7. Simplified conceptual flowsheet for the sandy desilication process with $\mathrm{Na}$ and Al recycled by sinter-leaching.

of the BR is now significantly upgraded. Sinterleaching a DSP concentrate stream addresses the major challenges of the serial combined Bayersinter process, as the $\mathrm{Al}$ and $\mathrm{Na}$ concentrations are increased and the $\mathrm{Fe}_{2} \mathrm{O}_{3}$ and other gangue concentrations are decreased. The benefits of sinter-leaching the DSP concentrate compared with the BR are:

- Lower mass flow, reducing the energy required for sintering

- Lower mass flow, reducing the unit operation size and associated capital cost

- Lower gangue mineral concentrations, which will minimize the negative impact of side reactions

- Lower gangue concentration, which will reduce the economic impact of side reaction control

- Higher recoveries of $\mathrm{Na}$ and $\mathrm{Al}$ from the sinter leach

- Ability to provide consistent and controlled feed product through sinter-leach

- The final $\mathrm{Ca}_{2} \mathrm{SiO}_{4}$-rich, low-Na residue may become a useful by-product, for example to be used as a component of cement manufacturing

- Through DSP enlargement, improved dewatering characteristics are expected, resulting in lower sinter feed moisture and associated energy savings.

\section{CONCLUSION}

The sandy DSP process concept is introduced to address the challenge of processing high-silica bauxite. In the sandy DSP process, the DSP is coarsened by reaction seeding and supersaturation control during an alternative Bayer pre-desilication stage. A DSP concentrate, obtained by physical separation from other components of the bauxite residue, is used as a feed material for the DSP concentrate sinter-leach process used to recover and recycle sodium hydroxide and aluminate to the Bayer process circuit. The sandy DSP process has the potential to significantly reduce costs associated with the bauxite residue sinter-leach process by lowering energy and reagent requirements. The sandy DSP process uses conventional processing equipment and solution chemistry, which is fully compatible with the Bayer process.

The sandy DSP process can be considered for bauxite high in reactive silica to help mitigate the costs associated with sodium hydroxide and improve environmental outcomes associated with residue storage and enable other residue reprocessing options.

It has been shown that DSP enlargement can be achieved in a timeframe consistent with conventional Bayer pre-desilication. The technology is in the early stages of development, and requires further research and development efforts to reduce technical risk prior to industrial implementation, however it holds significant potential for enabling economic production of alumina from high-silica ores. Other options can be considered for the DSP concentrate, such as to sell the material as a byproduct, or sulfuric acid leaching and electrolysis to recover sodium hydroxide and aluminum sulfate. 


\section{ACKNOWLEDGEMENTS}

We acknowledge financial support of this research by Rio Tinto through the University of Queensland Rio Tinto Bauxite and Alumina Technology Centre as well as from Advance Queensland. We acknowledge the facilities, and the scientific and technical assistance, of the Australian Microscopy \& Microanalysis Research Facility at the Centre for Microscopy and Microanalysis, The University of Queensland. We thank James Gudgeon for technical assistance in the University of Queensland Hydrometallurgy Laboratories. We thank Junyu Wang for preparing the graphical abstract. We thank Steve Healy, George Bánvölgyi, and Takuo Harato for technical feedback.

\section{REFERENCES}

1. K.J. Bayer, US Patent 382,505 (1888).

2. S. Ostap, Can. Metall. Q. 25, 101 (1986).

3. P. Smith, Hydrometallurgy 98, 162 (2009).

4. M. Gräfe, G. Power, and C. Klauber, Hydrometallurgy 108, 60 (2011).

5. K.J. Evans, Sustain. Metall. 2, 316 (2016).

6. R.S. Sherwin, JOM 2, 661 (1950).

7. R.G. Breuer, L.R. Barsotti, and A.C. Kelly, Extractive Metallurgy of Aluminum, vol. 1 (New York: Interscience, 1963), pp. 133-158.

8. H. Peng, D. Seneviratne, and J. Vaughan, Ind. Eng. Chem. Res. 57, 1408 (2018).

9. S. Seimiya, Extractive Metallurgy of Aluminum, vol. 1 (New York: Interscience, 1963), p. 115 .

10. H. Peng, M. Ding, and J. Vaughan, Ind. Eng. Chem. Res. 57 10292 (2018).

11. M. Jamialahmadi and H. Müller-Steinhagen, JOM 50, 44 (1998).

12. B. Xu, P. Smith, C. Wingate, and L. De Silva, Hydrometallurgy 105, 75 (2010).

13. G. Bánvölgyi, Proceedings of the 34th International Conference and Exhibition of ICSOBA, 3-6 October, 2016 (Quebec City, Canada. No 45, 2016), pp. 101-114.

14. T. Harato, T. Ogawa, and T. Ishida, US Patent No. $6,299,846$ (2001)

15. M. Tanjo, WO 93/20215. In Japanese (1993).

16. G. Bánvölgyi, Proceedings of the $2^{\text {nd }}$ International Bauxite Residue Valorisation and Best Practices Conference, Athens, 7-10/05/2018 (2018), pp. 69-78.

17. T. Harato, Proceedings of the Fourth International Alumina Quality Workshop (Darwin, Australia, AQW Inc., 1996).

18. T. Harato, T. Ishida, Y. Kumagae, M. Inami, K. Ishibashi, and Murakami M, US Patent No. 5,545,384 (1996).

19. G. Bánvölgyi, and P. Siklosi, Light Metals 1998, TMS, 45-53 (1998).

20. M.J. Hollitt, A.J. Crisp, W.S. Staker, G.M. Roe, and D.P.Rodda, US Patent No. 6,309,615 (2001).

21. B. Yang, J.G. Wang, Y.F. Zhang, and Y. Zhang, Chin. J. Process Eng. 7, 922 (2007).

22. J. Ma, Z. Li, and Q. Xiao, AIChE J. 58, 2180 (2012).

23. G. Power, M. Gräfe, and C. Klauber, Hydrometallurgy 108, 33 (2011).
24. C. Klauber, M. Gräfe, and G. Power, Hydrometallurgy 108, 11 (2011).

25. H. Peng, J. Vaughan, W. Staker, J. Wang, and W.Wen, Proceedings of Alumina2018, the 11th Alumina Quality Workshop, Gladstone, QLD, Australia, 9-14 September 2018 (AQW Inc., Australia, 2018).

26. T. Qi, H. Hodge, W. Hawker, P. Hayes, and J. Vaughan, Proceedings of Alumina2018, the 11th Alumina Quality Workshop, Gladstone, QLD, Australia, 9-14 September 2018 (AQW Inc., Australia, 2018).

27. H. Hodge, W. Hawker, P. Hayes, and J. Vaughan, First Global Conference on Extractive Metallurgy, Ottawa, Canada, 26-29 August 2018 (Cham, Switzerland: Springer International).

28. X. Li, N. Liu, T. Qi, Y. Wang, G. Liu, Q. Zhou, and Z.J. Peng, Central South Univ. 47, 2398 (2015).

29. L. Liu, L. Aye, Z. Lu, and P. Zhang, Energy 31, 1167 (2006).

30. B. Subotić, D. Škrtić, I. Šmit, and L. Sekovanić, J. Cryst. Growth 50, 498 (1980).

31. M.C. Barnes, J. Addai-Mensah, and A.R. Gerson, Colloids Surf. A 147, 283 (1999).

32. M.C. Barnes, J. Addai-Mensah, and A.R. Gerson, J. Cryst. Growth 200, 251 (1999).

33. M.C. Barnes, J. Addai-Mensah, and A.R. Gerson, Microporous Mesoporous Mater. 31, 287 (1999).

34. M.C. Barnes, J. Addai-Mensah, and A.R. Gerson, Colloids Surg. A: Physicochem. Eng. Asp. 157, 101 (1999).

35. J. Armstrong and S. Dann, Microporous Mesoporous Mater. 41, 89 (2000)

36. J. Addai-Mensah, A. Gerson, R. Jones, and M. Zbik, Light Metals, TMS, (2001).

37. J. Addai-Mensah, T. Khmeleva, and J.C. Thomas, Cryst. Growth Des. 13, 2260 (2013).

38. J. Addai-Mensah, J. Li, S. Rosencrance, and W. Wilmarth, J. Chem. Eng. Data 49, 1682-1687 (2004).

39. J. Addai-Mensah, J. Li, M. Zbik, and S. Rosencrance, Report No. WSRC-MS-2002-00907 (Westinghouse Savannah River Company, Savannah, GA, 2002).

40. F. Jones, and P. Smith, Proceedings of the 8th International Alumina Quality Workshop, Darwin NT Australia, 7-12 September (AQW Inc., 2008), pp. 100-102.

41. L. Zeng and Z. Li, Ind. Eng. Chem. Res. 51, 15193 (2012).

42. T. Radomirovic, P. Smith, D. Southam, S. Tashi, and F. Jones, Hydrometallurgy 137, 84 (2013).

43. S. Ruan, L. Shi, J. Li, and A.R. Gerson, Hydrometallurgy 169, 297 (2017).

44. D. Seneviratne, H. Peng, and J. Vaughan, Proceedings of the 35th ICSOBA Conference, 229-41, Hamburg, Germany, ICSOBA (2017).

45. G. Forte, and R. Dufour, Process for the removal of silica from an alkaline solution containing sodium aluminate. Patent WO/1999/067172 (2000)

46. T. Dyakowski, W. Kraipech, A.P. Nowakowski, and R. Williams, Proceedings of 2 nd International Conference on CFD, Melbourne, Australia (1999), pp. 205-210.

47. D.M. Hunter, J. Zhou, S.M. Iveson, and K.P. Galvin, Miner. Process. Extract Metall. 125, 126-131 (2016).

48. N. Oeberg, G.P. Kelton, and C.H. Rawlins, Light Metals, TMS, 143-150 (1996).

Publisher's Note Springer Nature remains neutral with regard to jurisdictional claims in published maps and institutional affiliations. 